\title{
Physical and Mathematical Modeling in Development of Metal Delivery System for Single Belt Casting Process
}

\author{
Ki-Hyeon MOON, Wung-Ryul CHOI, ${ }^{1)}$ Mihaiela ISAC, ${ }^{2)}$ Roderick I. L. GUTHRIE ${ }^{2)}$ and Hiroshi NOGAMI ${ }^{3)}$
}

McGill Metals Processing Centre, McGill University, M. H. Wong Building, 3610 University Street, Montreal, Quebec, H3A 2B2, Canada; on leave from POSCO Technical Laboratories, 699 Kuemho-dong, Kwangyang, Chunnam, 545-090, Korea. E-mail: Kihyeon.moon@mail.mcgill.ca 1) Formerly McGill Metals Processing Centre, now at POSCO, Kwangyang Works, 700 Kuemho-dong, Kwangyang, Chunnam, 545-010, Korea. 2) McGill Metals Processing Centre, McGill University, M.H. Wong Building, 3610 University Street, Montreal, Quebec, H3A 2B2, Canada.

E-mail: Roderick.Guthrie@mcgill.ca 3 3) Formerly McGill Metals Processing Centre, now at Institute of Multidisciplinary Research for Advanced Materials, Tohoku University, 2-1-1 Katahira, Aoba-ku, Sendai 980-8577 Japan.

(Received on November 22, 2002; accepted in final form on April 25, 2003)

\begin{abstract}
A piston type metal delivery system has been designed for the single belt strip caster at the McGill Metals Processing Centre (MMPC) of McGill University, and water modeling equipment set up to validate the proposed enclosed metal delivery system. Water flows were inspected using dye injection, and velocity fields were measured with a dual Nd: YAG PIV (Particle Image Velocimetry) system using the metal delivery nozzles proposed for optimum delivery of liquid steel. Mathematical modeling was also carried out to help anticipate flow patterns in the output chamber and the exit nozzle. When a slot type nozzle was used without a flow-modifier, a strong jet flow impinging on the substrate was generated. Bubbles generated during the initial filling of the delivery system were entrapped within re-circulatory flows in the output chamber. Bubbles were removed using a three hole type nozzle, but the impinging jet flow still remained. The FD type nozzle which had a multi-channel as a flow modifier, a slot type inlet nozzle located at the right side of the multi-channel, and an upper chamber which had the same height as the inlet slot length, was found to be outstanding for bubble removal, moderating strongly impinging flows, and providing uniform exit flows. Calculated flows were shown to be good agreement with PIV measurements.
\end{abstract}

KEY WORDS: single belt strip casting; metal delivery system; nozzle; fluid flow; PIV.

\section{Introduction}

Near net shape casting processes, which can eliminate the number of intermediate production steps or combine them in a continuous line, have been intensively studied for the last decade. Of the various near net shape casing processes for steel, the thin slab casting process using a stationary mold was successfully commercialized in 1990.1) The first commercial-scale twin roll casting process for carbon steel has been under construction since 2000 at Crawfordsville, USA. ${ }^{2)}$ However, the thin slab casting process has casting speed limitations caused by the friction force between the stationary mold and strand. ${ }^{1)}$ Similarly, twin roll casting has major issues in terms of productivity and microstructures. ${ }^{3)}$

An alternative approach is horizontal single belt casting. This process for casting 'thick' strips of steel has been reported to have a high productivity and to be suitable for all kinds of carbon steels and stainless steels, since the bending stresses and ferrostatic pressure that limit casting speeds in conventional continuous casting are removed. ${ }^{3)}$ However, the direct casting of strips pose a new set of challenges since casting speeds are an order of magnitude higher than those achieved in conventional and thin slab casting. This makes liquid metal delivery even more critical for the uniform distribution of evenly superheated liquid steel to the mold surface. ${ }^{4)}$

The delivery system for single belt casting must satisfy two requirements. One is to maintain constant thickness of the cast strip; the other is to stabilize the meniscus in the system. The inclined multi-hole arrangement and the argon rake with its integrated siphon are two satisfactorily performing delivery systems which have been developed by MEFOS and Clausthal. ${ }^{3)}$ However, the multi-hole nozzle arrangement leads to hydraulic jumps by impinging free jets onto the belt which could induce unstable meniscus. The argon rake system needs to set up another complicated system over the belt so that it could need large cost and maintenance difficulties. Herbertson and Guthrie ${ }^{5)}$ suggested an extended nozzle system using a porous brick as a flow modifier, but this system has the potential problems in terms of flowrate control and nozzle clogging.

A pilot scale Hazelett single belt caster has been installed at McGill University to study fluid flow in various delivery systems and associated solidification phenomena on the water cooled moving belt. In order to design the delivery system, a full-scale water model was set up. Several kinds of nozzles were proposed to optimize the tundish geometry 


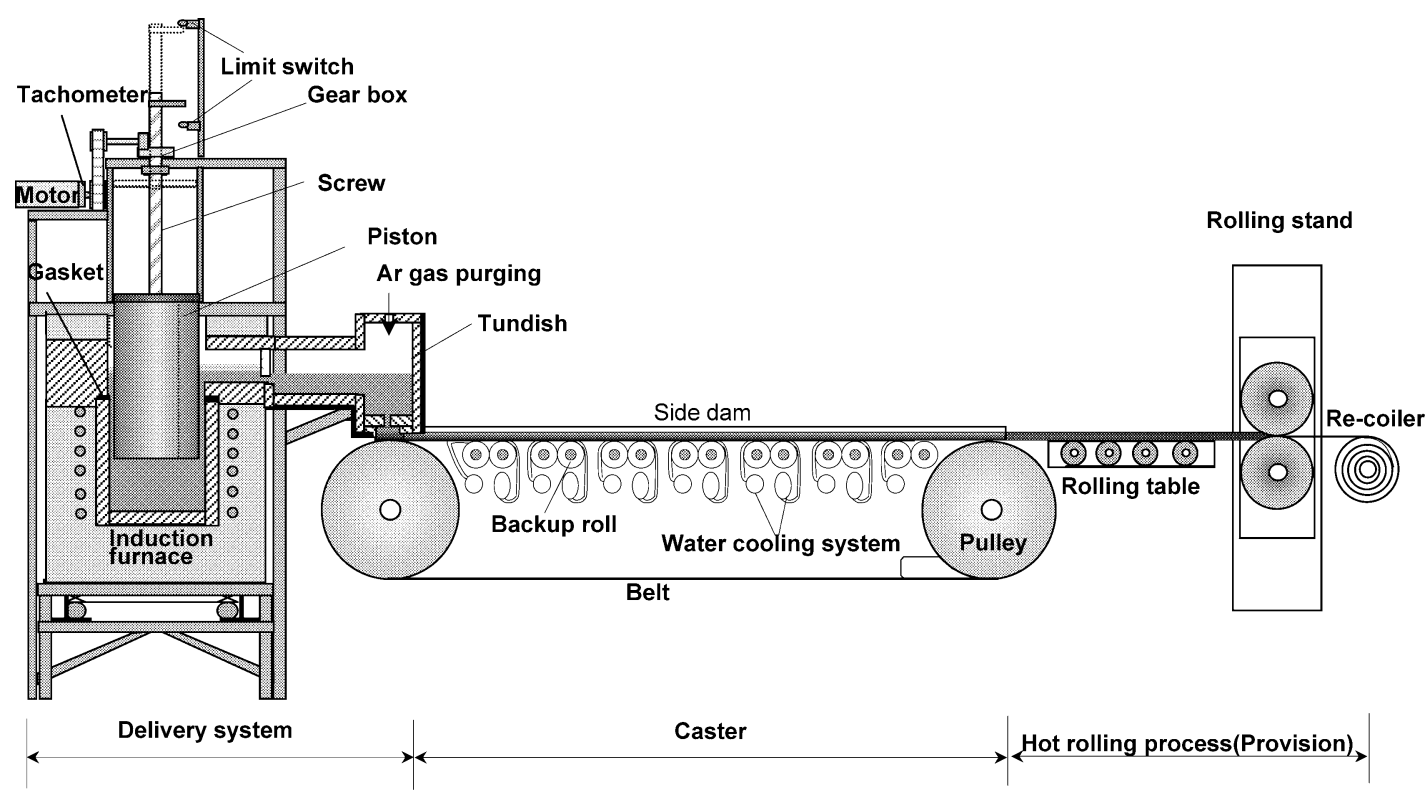

Fig. 1. Schematic diagram of the metal delivery system under construction for the single belt caster at the MMPC foundry.

of the metal delivery system. A dual Nd: YAG PIV system was used to visualize and quantify the water flow in the output chamber of the tundish. CFD (Computational Fluid Dynamics) calculations using FEMLAB (Version 2.3), a FEM (Finite Element Method) based commercial code, were also carried out to predict the velocity fields. The calculated results were compared with PIV measurements.

\section{Experimental Apparatus and Methods}

\subsection{Concept Design of a Metal Delivery System}

An upper positioned ladle with a stopper rod type flowrate controller is generally used as a metal delivery system for pilot scale single belt casting process. ${ }^{3,7)}$ However, a piston type was chosen as a metal delivery system for the MMPC foundry at McGill University which has space restrictions in terms of the height of the ceiling. This system is essential for a low cost, safe operation within a school laboratory.

Figure 1 provides a schematic of the metal delivery system conceived for the MMPC strip caster. The system involves a $500 \mathrm{lb}$ induction melting furnace, a cylinder shaped piston together with its driving system, and a tundish. The mold length of the caster is approximately 2.4 $\mathrm{m}$. The caster's maximum belt speed is $1.4 \mathrm{~m} / \mathrm{s}$ as shown in Table 1. A maximum casting speed of $0.4 \mathrm{~m} / \mathrm{s}$ was recorded with this caster for the production of $7 \mathrm{~mm}$ thickness, 200 $\mathrm{mm}$ wide at BHP Clayton Research Laboratories in Australia. When the piston, which has a slightly smaller diameter than the crucible, enters into the furnace, the melt, including slag, is displaced up through the channel between the crucible inner wall and the piston, and then flows into the tundish.

Figure 2 shows the proposed tundish. The "tundish" is composed of an entry chamber, a head control chamber and an output chamber which includes an exit nozzle. In the entry chamber, liquid metal passes though under a slag weir while slag is removed by this slag weir. A dam is installed
Table 1. Technical data of the single belt caster at the MMPC.

\begin{tabular}{c|l|l}
\hline \multicolumn{2}{c|}{ Items } & \multicolumn{1}{c}{ Specifications } \\
\hline \multirow{3}{*}{$\begin{array}{c}\text { Induction } \\
\text { Furnace }\end{array}$} & \multicolumn{1}{c}{$\begin{array}{c}\text { Capacity } \\
\text { Crucible size }\end{array}$} & $\begin{array}{l}500 \mathrm{lb}(227 \mathrm{Kg}) \text { for steel } \\
330 \mathrm{mmID} \times 508 \mathrm{mmH}\end{array}$ \\
\cline { 2 - 3 } & Temperature & Max. $1700^{\circ} \mathrm{C}$ \\
\hline \multirow{5}{*}{ Caster } & Mold length & $2438 \mathrm{~mm}$ \\
& Belt width & $368 \mathrm{~mm}$ \\
& Belt material & Low carbon steel/copper \\
\cline { 2 - 3 } & Belt speed & Max. $1.4 \mathrm{~m} / \mathrm{sec}$ \\
& Casting speed & Max. $0.28 \mathrm{~m} / \mathrm{sec}$ for $10 \mathrm{mmt}$ \\
\cline { 2 - 3 } & Strip thickness & $2-15 \mathrm{~mm}$ \\
& Strip width & Max. $200 \mathrm{~mm}$ \\
\hline
\end{tabular}

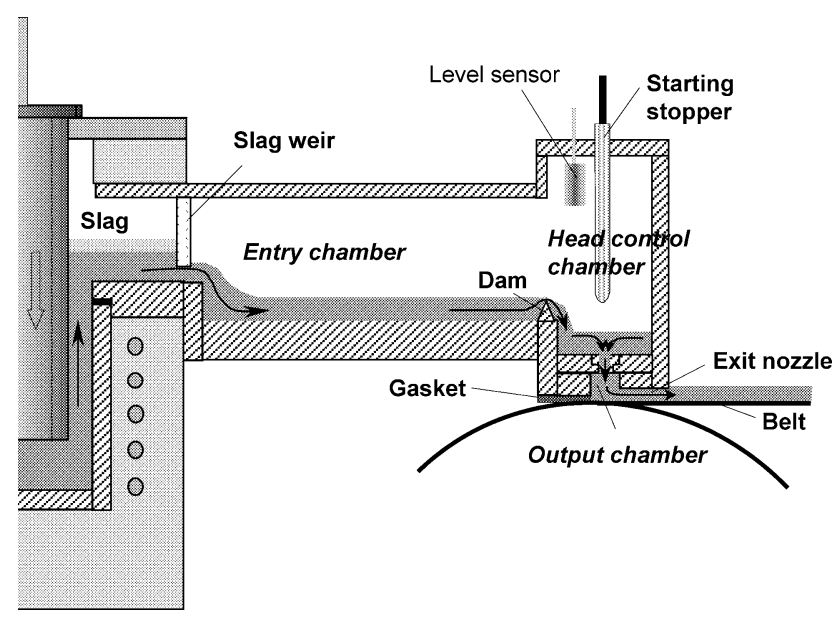

Fig. 2. Schematic diagram of the proposed metal delivery system.

at the front of the head control chamber so as to reduce turbulent inflow. A starting stopper was used for controlling the starting level within the head control chamber. A nozzle and an output chamber are installed at the bottom of the head control chamber so that liquid steel can be uniformly 
distributed to the belt and the exit nozzle. The output chamber acts as a mixing chamber so that turbulence can be dissipated in this chamber. At the gap between the bottom of the tundish and the belt, a thin ceramic wool pad, $2 \mathrm{~mm}$ thick, is inserted as a gasket to prevent backward penetration and freezing of liquid steel at the back wall of the output chamber.

\subsection{Water Model}

In order to evaluate the performance of the proposed tundish with respect to fluid flow, water modeling was crucial. Water models are widely used for steel because the kinematic viscosity of liquid steel, $v_{\text {steel at } 1550^{\circ} \mathrm{C}}=1.0 \times 10^{-6}$ $\mathrm{m}^{2} / \mathrm{s}$, is almost same as that of water at room temperature, $v_{\text {water at } 20^{\circ} \mathrm{C}}=0.98 \times 10^{-6} \mathrm{~m}^{2} / \mathrm{s}$. The water model equipment was constructed of transparent acrylic for visualization of the fluid flow. Since the amount of metal $(227 \mathrm{~kg}$ for steel) and casting width is not great $(200 \mathrm{~mm})$, full scale modeling to simultaneously satisfy both Froude and Reynolds similarity criteria, was easily possible. Of the various components of this proposed "tundish", the output chamber and nozzle were the most important factors since the distribution of liquid steel onto the belt is finally determined in the output chamber. Figure 3 provides a schematic of the water model apparatus. It was composed of the "tundish", a substrate, a flow meter and a few control valves. The "tundish" consisted of a head control chamber, and an output chamber which included an exit nozzle. Although this static model had no input chamber and no moving substrate, it is

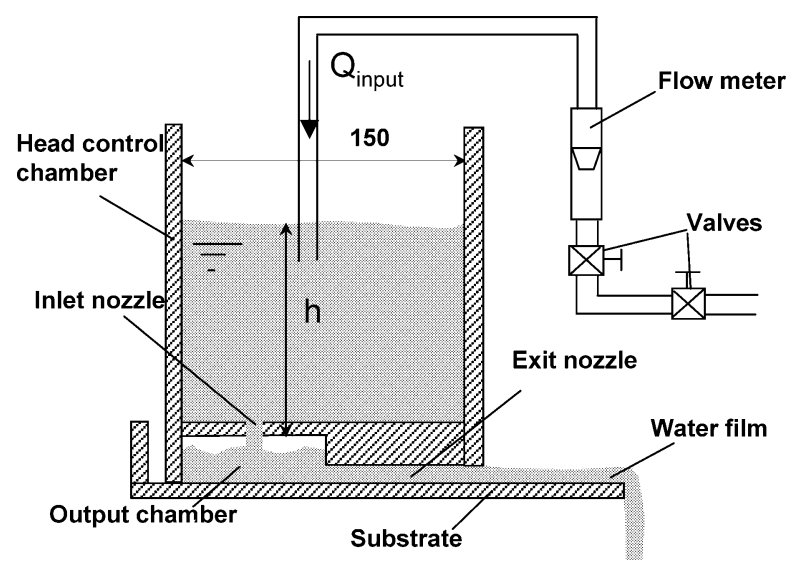

Fig. 3. Schematic diagram of the tundish used for experiments on a static substrate. sufficient to evaluate the performance of the various nozzles and output chambers proposed. The size of the head control chamber was $150 \mathrm{~mm} \mathrm{~L} \times 250 \mathrm{~mm} \mathrm{~W} \times 200 \mathrm{~mm} \mathrm{H}$, the output chamber $70 \mathrm{~mm} \mathrm{~L} \times 200 \mathrm{~mm} \mathrm{~W} \times 25.5 \mathrm{~mm} \mathrm{H}$, and the exit nozzle $92 \mathrm{~mm} \mathrm{~L} \times 200 \mathrm{~mm} \mathrm{~W} \times 10 \mathrm{~mm} \mathrm{H}$. Six types of nozzle were selected for investigation (see Table 2). Water flows were visualized by the injection of red dye. Bubble behavior was inspected visually and recorded with a Nikon FM2 camera.

\subsection{Dual Nd: YAG PIV System}

The water flows and vector fields in the output chamber were measured and analyzed using a dual Nd: YAG PIV system. As shown in Fig. 4, the PIV system is composed of a dual Nd: YAG laser head including optics, two laser power supplies, a synchronizer, a high resolution CCD camera and a computer system. The PIV technique is based on illuminating and tracking the tracer particles added to the fluid using a pulsed laser. The Dual laser system can trigger the lightsheet twice in a given time interval with the synchronizer. The function of the synchronizer is timing and system controller. It synchronizes the timing of image capture with the pulsing of the laser. A CCD camera positioned perpendicular to the lightsheets captures the particle images and records them on the computer. The computer system, which has an INSIGHT Ultra software, can calculate and display a two dimensional vector field from the particle image fields.

Table 3 provides technical data of the PIV system used for these experiments. The laser's maximum power of this PIV was $200 \mathrm{~mJ}$, which proved sufficiently strong for measuring water flows for the "tundish". This PIV also triggers laser $15 \mathrm{~Hz}$ repetition rate and works well with a $17 \mathrm{~Hz}$, $2048 \times 2048$ pixel CCD camera.

The image displacements were obtained using the spatial cross-correlation method. Figure 5 shows the cross-correlation processes. Using the dual laser, the two images are captured on the separate frames so that the image created by the first laser pulse is clearly separated from that created by the second pulse. The particle displacement is obtained with the cross-correlation of the two images within the interrogation region. The direction of fluid displacement is then quite clear because it is from the image in the first frame to that in the second frame as shown in Fig. 5. This process is repeated for all the interrogation regions to obtain the displacement in the flow region. The velocity can

Table 2. Dimensions of various nozzles used for the experiments.

\begin{tabular}{|c|c|c|c|c|c|c|}
\hline & & & & & & Unit: $\mathrm{mm}$ \\
\hline & \multicolumn{2}{|c|}{ Inlet nozzle } & \multicolumn{3}{|c|}{ Output chamber } & \multirow{2}{*}{$\begin{array}{c}\text { Exit nozzle } \\
(\mathrm{L} \times \mathbf{W} \times \mathrm{H})\end{array}$} \\
\hline & Type & $\begin{array}{c}\text { Size } \\
(L \times W)\end{array}$ & $\begin{array}{c}\text { Multi- } \\
\text { channel } \\
(\mathrm{L} \times \mathrm{W} \times \mathrm{H})\end{array}$ & $\begin{array}{l}\text { Upper } \\
(\mathrm{L} \times W \times H)\end{array}$ & $\begin{array}{l}\text { Lower } \\
(\mathrm{L} \times W \times H)\end{array}$ & \\
\hline TypeA & Slot & $2.4 \times 200$ & No & \multicolumn{2}{|c|}{$70 \times 200 \times 25.5$} & $100 \times 200 \times 10$ \\
\hline Tyрев & 3-hole & $14.5 \phi$ & No & \multicolumn{2}{|c|}{$70 \times 200 \times 25.5$} & $100 \times 200 \times 10$ \\
\hline $\begin{array}{c}\text { Type } \\
\text { FA,FB,FC }\end{array}$ & Slot & $3.2 \times 200$ & $\begin{array}{c}27 \times 200 \times 6 \\
(10 \text { ppi })\end{array}$ & $38 \times 200 \times 9.5$ & $27 \times 200 \times 10$ & $100 \times 200 \times 10$ \\
\hline $\begin{array}{l}\text { Type } \\
\text { FD }\end{array}$ & $\begin{array}{l}\text { Slot with } \\
\text { angle }\end{array}$ & $\begin{array}{c}3.2 \times 200 \\
\left(45^{\circ}\right)\end{array}$ & $\begin{array}{c}27 \times 200 \times 6 \\
(10 p p i)\end{array}$ & $38 \times 200 \times 3.2$ & $27 \times 200 \times 10$ & $100 \times 200 \times 10$ \\
\hline
\end{tabular}




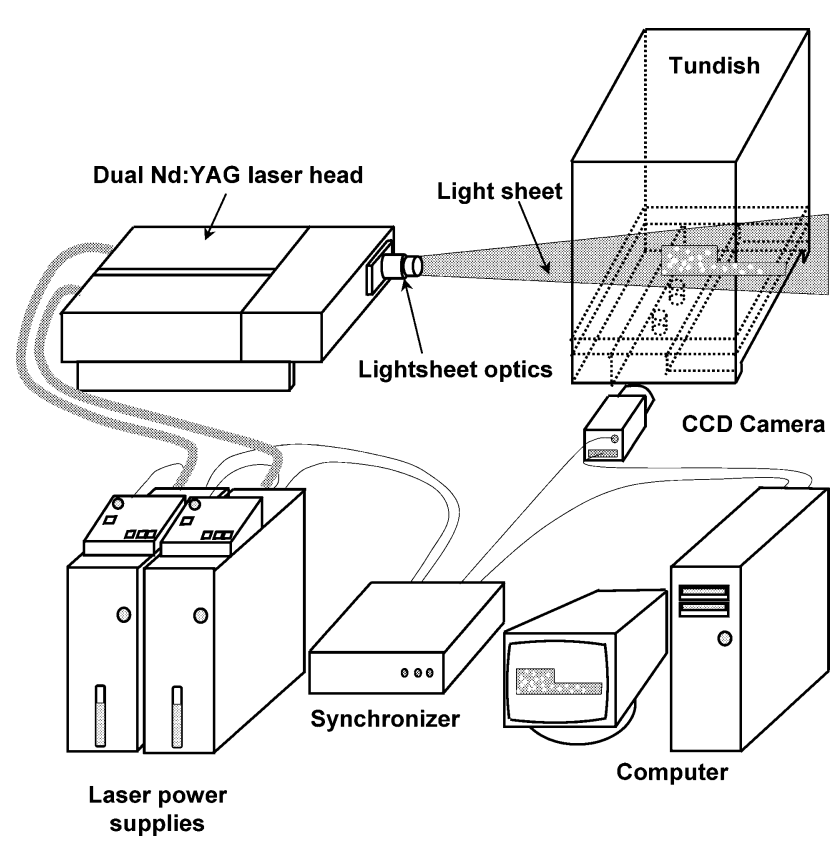

Fig. 4. Schematic diagram of the Dual Nd: YAG PIV.

Table 3. Technical data of the PIV.

\begin{tabular}{l|l|l}
\hline \multicolumn{2}{c|}{ Items } & \multicolumn{1}{c}{ Specification } \\
\hline Laser & Model & Mini dual Nd:YAG \\
& Pulse energy & $200 \mathrm{~mJ} /$ pulse \\
& Flash lamp frequency & $15 \mathrm{~Hz}$ \\
\hline Camera & Model & Power View 12-bit \\
& Pixel & $2048 \times 2048$ \\
& Frame rate & $17 \mathrm{~Hz}$ \\
\hline
\end{tabular}
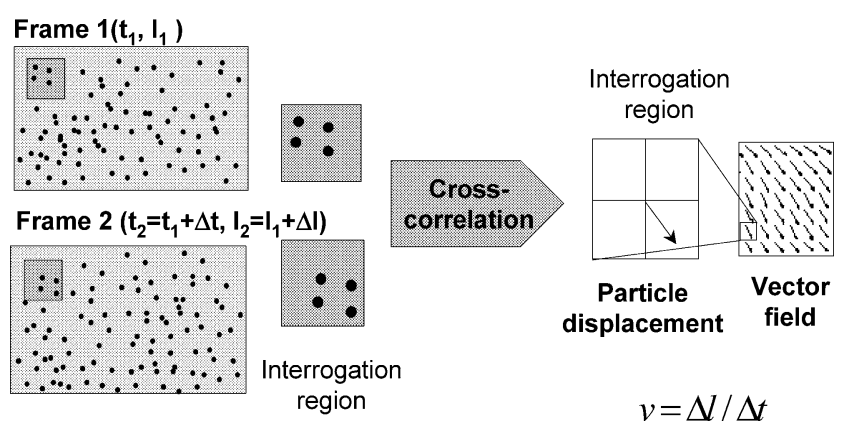

Fig. 5. Cross-correlation process for the PIV.

be achieved with this measured displacement and the laser's pulse separation time.

The cross-correlation technique needs a special CCD camera and a frame straddling technique to capture the two frames with the short pulse separation time interval, $\Delta t$. As shown in Fig. 6, the basic principle of "frame-straddling" is to make the first laser pulse toward the end of the first frame of the camera and then to make the second laser pulse at the beginning of the second frame. Very small value of $\Delta t$, less than $0.5 \mu \mathrm{s}$, can thereby be obtained so that high speed flows (over $400 \mathrm{~m} / \mathrm{s}$ ) can be measured using this PIV. To position the first laser pulse at the end of the first frame, a "pulse delay" is required. This value can be set in the software for each case of measurement. ${ }^{8)}$

As shown in Fig. 4, to capture the scattered particle

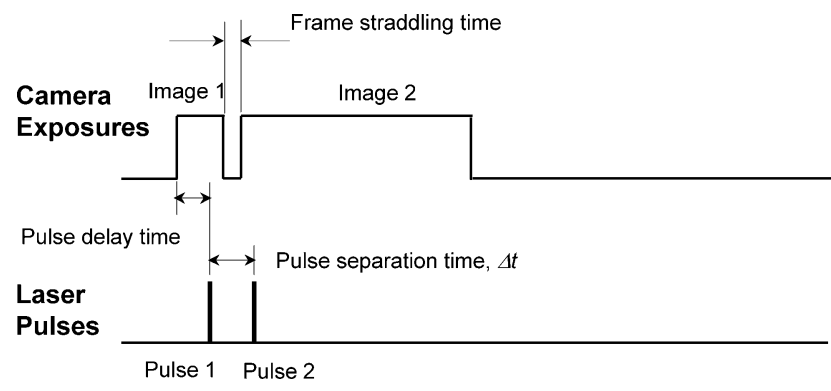

Fig. 6. Frame straddling technique for the PIV.

image in the output chamber, the 12-bit CCD camera was set up perpendicular to the lightsheet. The time interval of the two pulses was set to $300 \mu \mathrm{s}$ and $400 \mu \mathrm{s}$. The pulse delay time was set to $0.5 \mathrm{~ms}$. As seed particles for light reflection, alumina powder comprising $5 \mu \mathrm{m}$ diameter spheres was used.

\subsection{Mathematical Modeling}

Mathematical modeling is required to predict fluid flows within the output chamber. A commercial two-dimensional finite element model, FEMLAB (Version 2.3), was used to calculate the fluid flow.

The flow was assumed to be steady, incompressible, and two-dimensional. End effects were ignored. The filter (or flow modifier) was not considered as a porous medium but rather as a multi channel because its pore size is large enough, $2.2 \mathrm{~mm} \times 2.2 \mathrm{~mm}$, and porosity is very high, $81 \%$.

Under these assumptions, the continuity equation and the turbulent Navier-Stokes equation were used as governing equations. The continuity equation for the conservation of mass can be expressed in the form:

$$
\frac{\partial}{\partial x_{i}}\left(\rho u_{i}\right)=0
$$

The turbulent Navier-Stokes equation for momentum balance equation can be expressed for steady state, incompressible fluid flow as:

$$
\frac{\partial}{\partial x_{j}}\left(\rho u_{i} u_{j}\right)=-\frac{\partial P}{\partial x_{i}}+\frac{\partial}{\partial x_{j}}\left[\mu_{\mathrm{eff}}\left(\frac{\partial u_{i}}{\partial x_{j}}+\frac{\partial u_{j}}{\partial x_{i}}\right)\right]+\rho g_{i}
$$

where effective viscosity $\mu_{\text {eff }}=\mu_{0}+\mu_{\mathrm{t}}$ and turbulent viscosity; $\mu_{\mathrm{t}}=C_{\mu} k^{2} / \varepsilon ; \mu_{0}=$ molecular viscosity, $C_{\mu}=$ turbulence model constant, $k=$ turbulence kinetic energy, and $\varepsilon=$ the rate of dissipation of turbulence energy.

The standard $k-\varepsilon$ model is one of the most popularly used turbulence models for industrial applications. In this model, two extra transport equations were solved for the turbulence kinetic energy, $k$, and the rate of dissipation of turbulence energy, $\varepsilon^{9)}$

Turbulent kinetic energy equation:

$$
\frac{\partial}{\partial x_{j}}\left(\rho u_{j} k\right)=\frac{\partial}{\partial x_{j}}\left[\mu_{\mathrm{eff}}\left(\frac{\partial k}{\partial x_{j}}\right)\right]+\mu_{t} \frac{\partial u_{i}}{\partial x_{j}}\left(\frac{\partial u_{i}}{\partial x_{j}}+\frac{\partial u_{j}}{\partial x_{i}}\right)-\rho \varepsilon
$$

where $\mu_{\text {eff }}=\mu_{0}+\mu_{\mathrm{t}} / \sigma_{k} ; \sigma_{k}=$ turbulence model constant.

Dissipation rate of turbulence equation: 


$$
\begin{aligned}
& \frac{\partial}{\partial x_{j}}\left(\rho u_{j} \varepsilon\right)=\frac{\partial}{\partial x_{j}}\left[\mu_{\mathrm{eff}}\left(\frac{\partial \varepsilon}{\partial x_{j}}\right)\right] \\
& +C_{\varepsilon 1} \mu_{\mathrm{t}} \frac{\partial u_{i}}{\partial x_{j}}\left(\frac{\partial u_{i}}{\partial x_{j}}+\frac{\partial u_{j}}{\partial x_{i}}\right) \cdot\left(\frac{\varepsilon}{k}\right)-C_{\varepsilon 2} \rho \frac{\varepsilon^{2}}{k}
\end{aligned}
$$

where $\mu_{\text {eff }}=\mu_{0}+\mu_{\mathrm{t}} / \sigma_{\varepsilon} ; \sigma_{\varepsilon}=$ turbulence model constant.

The model constants for the equations of the $k-\varepsilon$ turbulence model were determined from experimental data ${ }^{9)}$ and were set to

$$
C_{\mu}=0.09, \quad C_{\varepsilon 1}=1.44, \quad C_{\varepsilon 2}=1.92, \quad \sigma_{k}=1.0, \quad \sigma_{\varepsilon}=1.3
$$

The following boundary conditions of the computational domain were adopted for the fluid flow:

- At the inlet of the output chamber, the vertical velocity, $V$, was specified as $V_{\text {in }}$, while the horizontal component of the velocity, $U$, was set to zero. The initial values for the turbulence variables $\left(k_{\text {in }}, \varepsilon_{\text {in }}\right)$ were taken from the literature $^{9)}$ and were represented at Eq. (5).

$$
k_{\text {in }}=0.005 V_{\text {in }} ; \quad \varepsilon_{\text {in }}=0.09 \frac{k_{\text {in }}^{1.5}}{0.03 \delta}
$$

where $\delta$ represents the size of the inlet nozzle.

- For the boundary layer near the tundish walls, the law of the wall was applied so as to smoothly connect the turbulent dominated region of the flow with the viscous dominated region near these walls of the flow system. This model is known to be accurate for high Reynolds number. ${ }^{11,12)}$ Applying to the present system, boundary conditions for $k$ and $\varepsilon$ near wall were represented as:

$$
k=\frac{u_{\tau}^{2}}{\sqrt{C_{\mu}}} ; \quad \varepsilon=\frac{u_{\tau}^{2}}{\kappa y}
$$

where Von Karman's constant $\kappa=0.41$ and $u_{\tau}=$ friction velocity.

- At the all walls, a "no-slip" condition was employed. The kinetic energy was also specified to be zero.
- At the outlet, fully-developed flow was considered.

- Density of water, $\rho=1000 \mathrm{~kg} / \mathrm{m}^{3}$; molecular viscosity, $\mu_{0}=0.001 \mathrm{~kg} / \mathrm{m} \cdot \mathrm{s}$

Calculated flow field were compared with those measured using PIV system.

\section{Results and Discussion}

\subsection{Water Modeling and PIV Measurement}

As shown in Table 2, six types of inlet nozzle and output chamber were tested. Two kinds of inlet nozzle such as a slot type and a three-hole type nozzle were used for these experiments. The effect of the multi-channel type flow modifier was also investigated with the slot type inlet nozzle. The slot sizes were $2.4 \mathrm{~mm} \times 200 \mathrm{~mm}$ for the A type nozzle which had an output chamber of simple rectangular shape, and $3.2 \mathrm{~mm} \times 200 \mathrm{~mm}$ for the $\mathrm{F}$ type series nozzles such as FA, FB, FC and FD types. These had the output chambers using flow modifiers. A hole-type nozzle, Type B, had three $14.5 \mathrm{~mm}$ holes. These nozzle sizes were designed to raise the water level to $60 \mathrm{~mm}$ within the tundish when the flowrate was $34 \mathrm{~L} / \mathrm{min}$. This flowrate is equivalent to casting strip, $200 \mathrm{~mm}$ width and $10 \mathrm{~mm}$ thickness, at a speed of $0.28 \mathrm{~m} / \mathrm{s}$. The start-up of the cast was begun at a higher head level of $150 \mathrm{~mm}$ so as to achieve a closed pool in the output chamber as rapidly as possible. For obtaining the starting level in the tundish, a starting stopper system was used. The PIV measurements were also carried out for both types of nozzle with and without the flow modifier.

Figure 7 shows the flow patterns visualized by dye injection and PIV measurements. As shown in Fig. 7, large bubbles were observed ahead of the main stream entering via the slot nozzle. These bubbles remained for more than 10 $\mathrm{min}$ at a flowrate of $34 \mathrm{~L} / \mathrm{min}$. The bubbles were originally generated by air entrainment during initial impingement of the jet flow entering the unfilled pool of the output chamber. Figure 7(b) shows the measured vector field in the output chamber. The entry flow divided into two opposing recirculatory flows after strong impingement on the substrate.

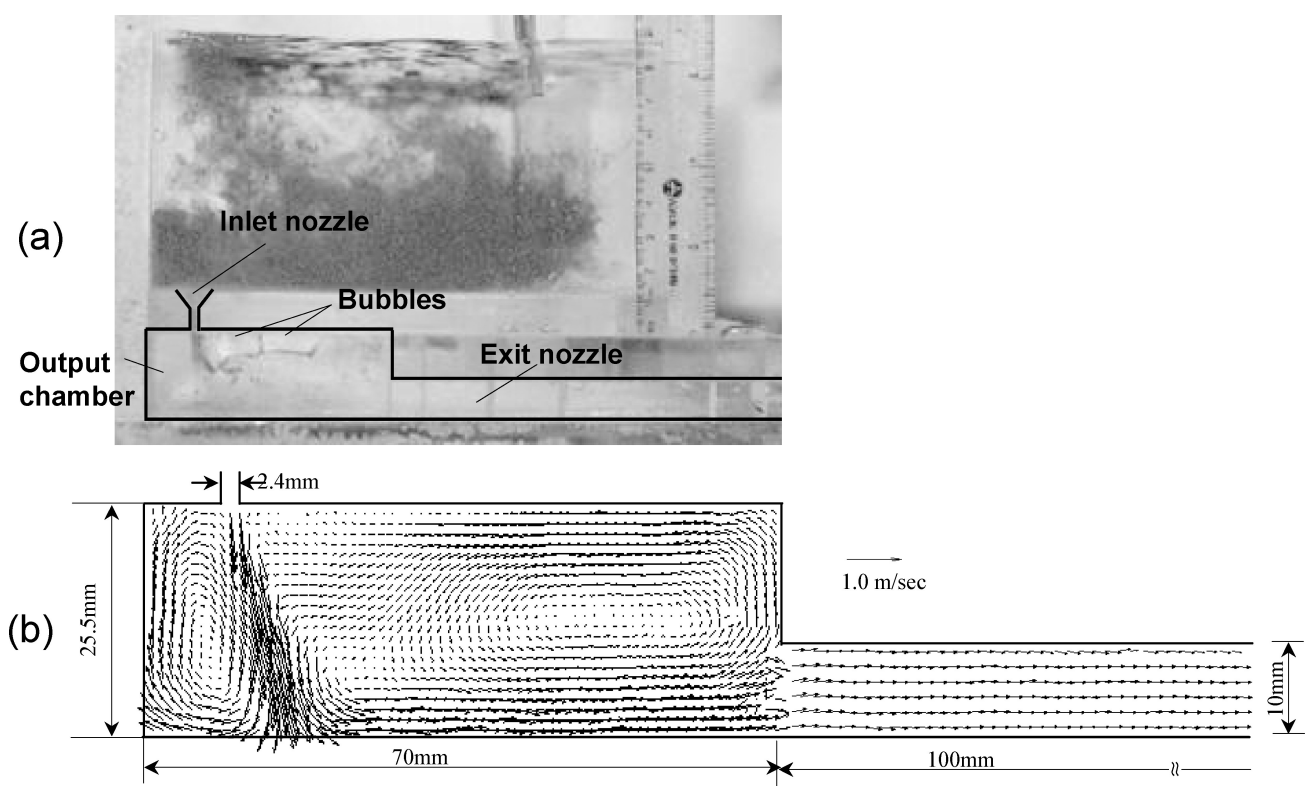

Fig. 7. Flow visualization in the output chamber for the A type nozzle by (a) dye injection and (b) PIV measurements. 


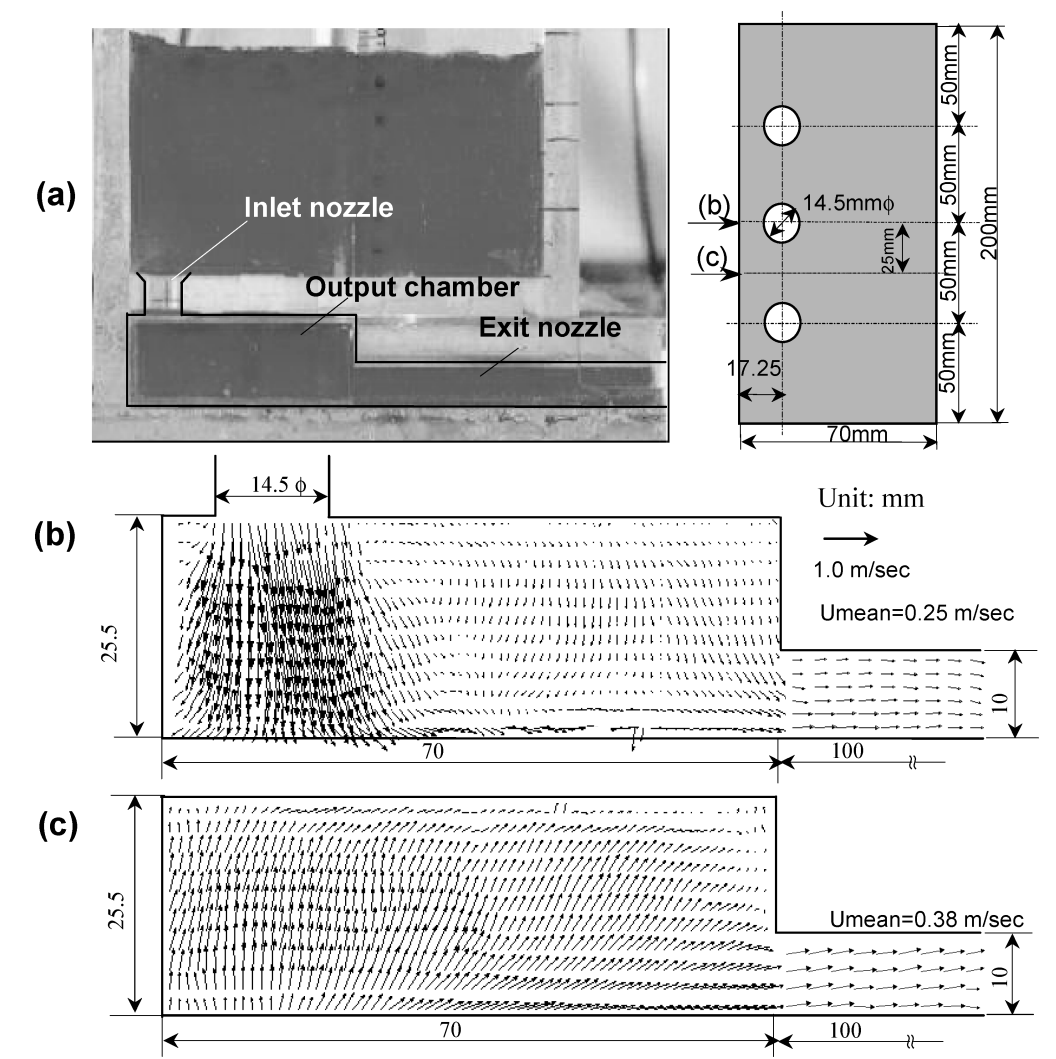

Fig. 8. Flow visualization in the output chamber for the B type nozzle by (a) dye injection, and (b), (c) PIV measurements: (b) below the hole, and (c) between the holes.

This strongly impinging flow could disturb the formation of a sound meniscus and remelt the forming shell of metal solidifying on the belt. Downstream of the impinging flow, a dead zone was observed which coincided with the bubble entrapment zone.

To avoid these re-circulatory flows, dead zones and associated bubble entrapment, a 3-hole type (or Type B) nozzle was proposed and tested. Figure 8 shows the visualized water flow in the output chamber under the B type nozzle. Figure 8(a) reveals the output chamber was fully filled so that no bubbles remained after $20 \mathrm{~s}$. Two PIV measurements were carried out to compare the velocity field in the output chamber and the uniformity of the exit flow in the exit nozzle. One measurement Fig. 8(b) was in the output chamber below the center hole, the other Fig. 8(c) was in the output chamber between the center hole and an edge hole, as shown in the right side of the picture in Fig. 8(a). As shown in Fig. 8(b), in the output chamber below the center hole, strong impinging jets were generated. However, re-circulatory flows were avoided. The flow between the center hole and edge hole was upwardly directed (Fig. 8(c)). This upwardly directed flow was generated by laterally colliding flows from the nozzle holes. Although the bubbles were easily removed with this 3-hole nozzle, the exit velocity distribution across the width was not uniform since exit axial velocities in-between the holes were faster than those in the transverse vertical planes intersecting the holes. In order to prevent the strong impingement against the substrate, a multi-channel type flow modifier was proposed for the output chamber.

\subsection{Mathematical Modeling}

Before water modeling for the proposed nozzles which have a flow modifier, mathematical modeling using FEMLAB was carried out to predict water flow and find out the optimum geometry of the inlet nozzle and the output chamber. The multi-channel measured $27 \mathrm{~mm} \mathrm{~L} \times 200 \mathrm{~mm} \mathrm{~W} \times 6$ $\mathrm{mm} \mathrm{H}$, while each channel size was $2.2 \mathrm{~mm} \times 2.2 \mathrm{~mm}(10$ ppi). Each channel was large enough not to make flow resistance inside the channels. A slot type nozzle was chosen as an inlet nozzle for better uniformity of flow distribution. The size of the slot nozzle was set to $3.2 \mathrm{~mm} \mathrm{~L} \times 200 \mathrm{~mm}$ W. The multi-channel was installed in the middle of the output chamber since an upper chamber was needed above the multi-channel for the distribution of flow entering thorough the inlet nozzle. For uniform distribution of the inlet flow, the position of the inlet nozzle and the height of the upper chamber needed specifying. The height of the lower chamber under the channel was fixed to $10 \mathrm{~mm}$, the same height as that of the exit nozzle. Firstly, the calculation was carried out for the FA type nozzle: the height of the upper chamber over the multi-channel was set to $9.5 \mathrm{~mm}$, and the nozzle, set vertically to the output chamber, was positioned at the center of the upper chamber.

Figure 9(a) shows calculated results for the FA type nozzle. After impinging on the top of the multi-channel, the main stream came down through only a few channels, and then impinged the belt surface. Although this impinging jet flow was reduced by the multi-channel, it was not sufficient for even distribution of the exit flow. The FB type nozzle, in which the inlet nozzle was positioned to the left side (or back side) of the upper chamber and had an impact bottom for guiding the inlet flow, was tested. As shown in Fig. 9(b), 


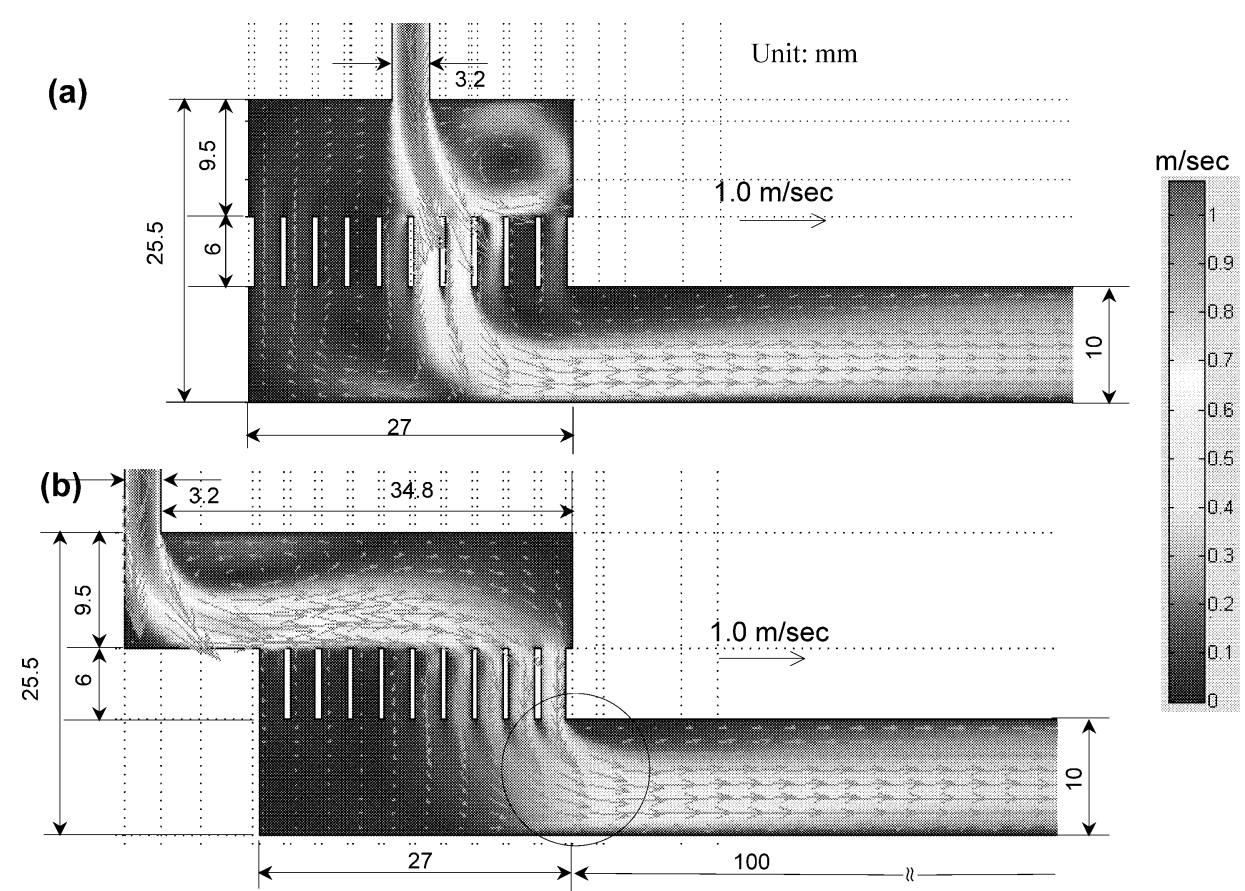

Fig. 9. Mathematical modeling for the multi-channel type of nozzles: (a) Type FA, (b) Type FB.

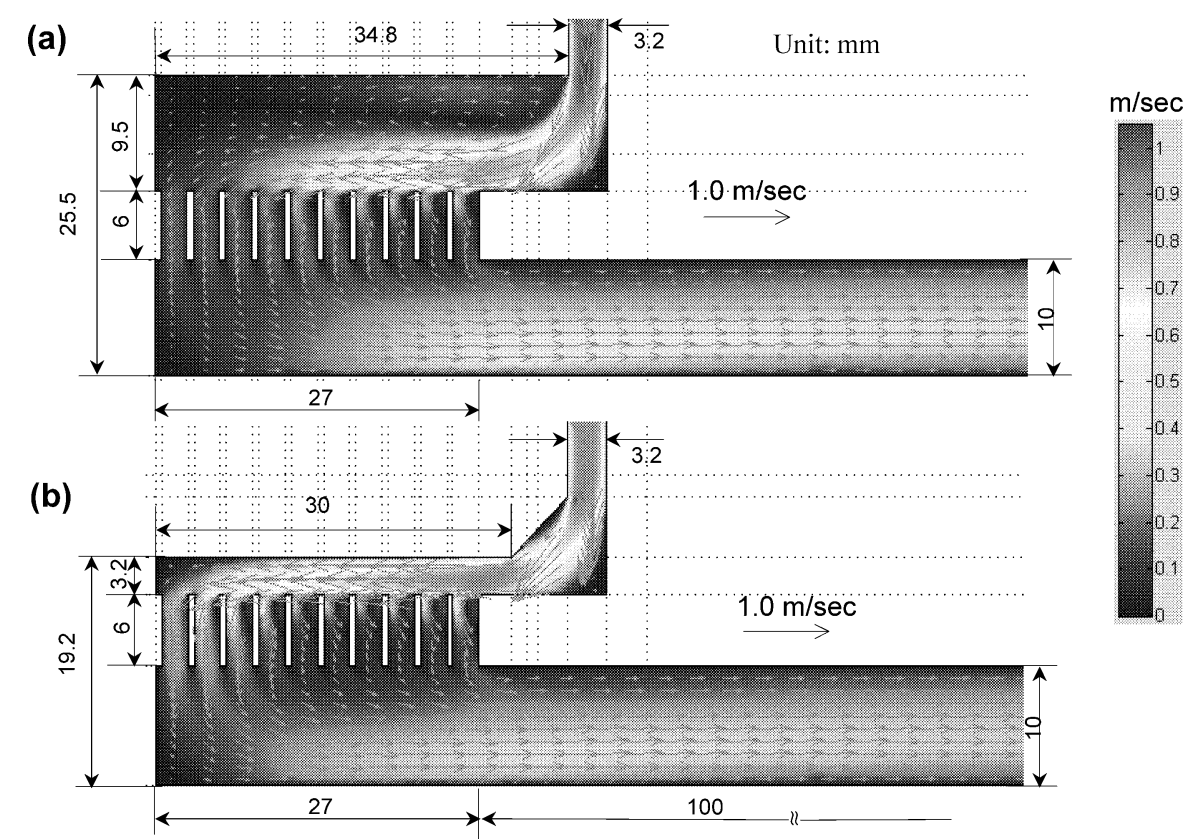

Fig. 10. Mathematical modeling for the multi-channel type of nozzles: (a) FC type, (b) FD type.

the main stream from the inlet nozzle hit the impact bottom and then bent, flowed into the upper chamber. During passage through the upper chamber, the stream mainly came down through the multi-channel, but a flow separated from the main stream showed a small re-circulatory flow which could entrap bubbles. In the output chamber below the multi-channel, the impinging jet flow disappeared because turbulence energy was dissipated by this flow modifier. However, the flow penetrating the channels was not uniformly distributed. It mainly came down through the front side (or right side) of the multi-channel, and then caused a strong, vertical flow which disturbed the horizontal flow in the exit nozzle, as shown in the circle of Fig. 9(b).

To avoid this problem, the nozzle position was moved to the right side of the multi-channel with the impact bottom (Type FC). As shown in Fig. 10(a), the stream entering from the inlet nozzle came down through the multi-channel more uniformly, and then flowed into the exit nozzle horizontally. Although the exit flow was uniformly distributed, a re-circulatory flow, which could entrap bubbles, was generated in the upper part of the output chamber.

To prevent this re-circulatory flow, the FD type nozzle was proposed: the height of the upper part of the output chamber was reduced to $3.2 \mathrm{~mm}$, the same size as the slot length, and the angle $\left(45^{\circ}\right)$ was set between the vertical slot and the horizontal upper chamber for smoother bending flow as shown in Fig.10(b). The re-circulatory flow was completely removed. Moreover, the stream mainly came 

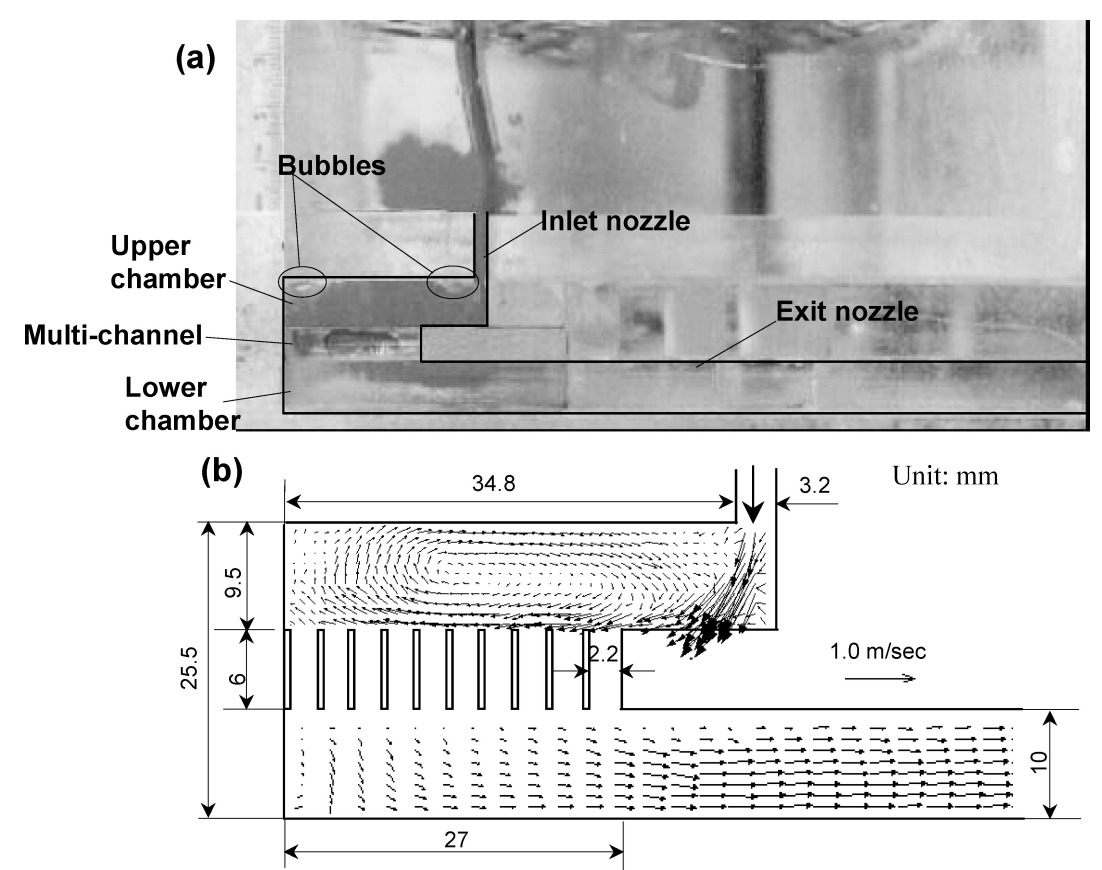

Fig. 11. Flow visualization in the output chamber for the FC type nozzle: by (a) dye injection and (b) PIV measurements.

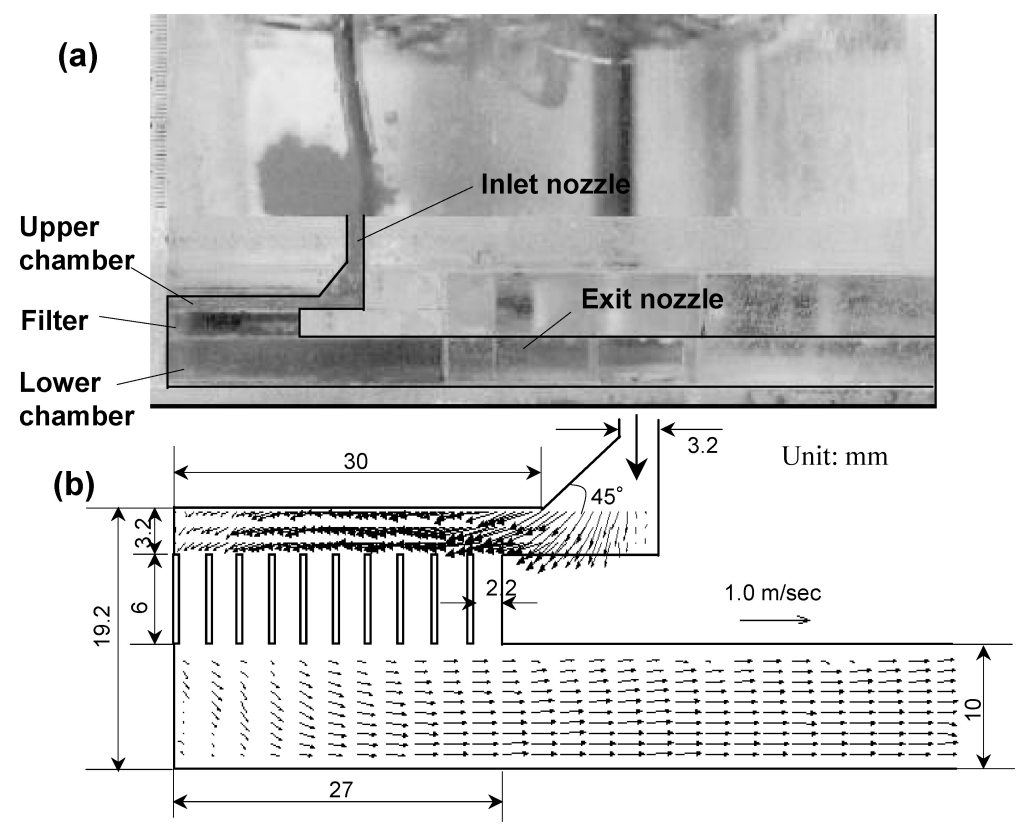

Fig. 12. Flow visualization in the output chamber for the optimized nozzle (FD type): by (a) dye injection and (b) PIV measurements.

down the back side of the multi-channel so that the horizontal exit flow was more easily achieved than the FC type nozzles. This flow pattern gave more kinetic energy to the back side corner of the output chamber. This measure could help preventing metal freezing at the back wall of the metal delivery system.

\subsection{Optimum Nozzle and Output Chamber}

To validate the flow patterns for the multi-channel type nozzles, water modeling and PIV measurements were carried out. Figure 11(a) shows a visualization using dye injection while Fig. 11(b) a corresponding velocity field obtained from PIV measurements for the FC type nozzle. As shown in Fig. 11(a), the bubbles remained in the left and right corner of the upper chamber during the test period (10 min). The PIV measurements showed good agreement with the calculation results shown in Fig. 10(a). A re-circulatory flow was detected in the upper part of the output chamber, and mostly horizontal flow was measured along the whole exit nozzle.

Figure 12 shows the performance of the FD type nozzle. This nozzle had a lower height of the upper chamber, 3.2 $\mathrm{mm}$, and a $45^{\circ}$ slope at the end of the inlet nozzle to prevent flow re-circulation and a dead zone. Bubbles were completely removed from the output chamber within $5 \mathrm{~s}$ after starting pouring at $150 \mathrm{~mm}$ level as shown in Fig. 12(a). Figure 12(b) shows PIV measurements. In the upper part of the output chamber, re-circulatory flows and dead 
zones were not generated so that bubbles were easily removed. The impact of the vertically flowing jet against the substrate was dramatically reduced so that the horizontal flow in the lower part of output chamber began earlier (i.e. closer to the back wall) than was the case with the FC type nozzle.

Figure 13 compares of calculated and measured velocities along the length of the output chamber and exit nozzle. The positions compared were $5 \mathrm{~mm}$ above the substrate in both the output chamber and exit nozzle. As shown in Fig. 13, good agreement was achieved between the experiments and the computations. On the basis of this agreement, computations of velocity fields were implemented with moving belt within the output chamber and the exit nozzle of the FD type nozzle including outside the exit nozzle. The upper boundary of the water film at the outside of the exit nozzle was set to a free surface condition. Belt speed was set to $0.28 \mathrm{~cm} / \mathrm{s}$. Figure 14 shows calculated results. The predicted velocity distribution on the outside of the exit nozzle is quite uniform across the thickness of the water film. Figures 15(a), 15(b), 15(c) and 15(d) provide velocity distributions of the water film formed on the moving belt with different distance from the back wall of the output chamber. The positions for comparison are indicated in Fig. 14. As shown in Fig. 15(a), at $5 \mathrm{~mm}$ away from the back wall, the average velocity of water flow is $0.18 \mathrm{~m} / \mathrm{s}$, slightly lower than the belt speed. However, the average velocities increase with increasing distance from the back wall. In addition, at the entrance of the exit nozzle (or $30 \mathrm{~mm}$ away from the back wall) and at the exit of the exit nozzle (or $120 \mathrm{~mm}$

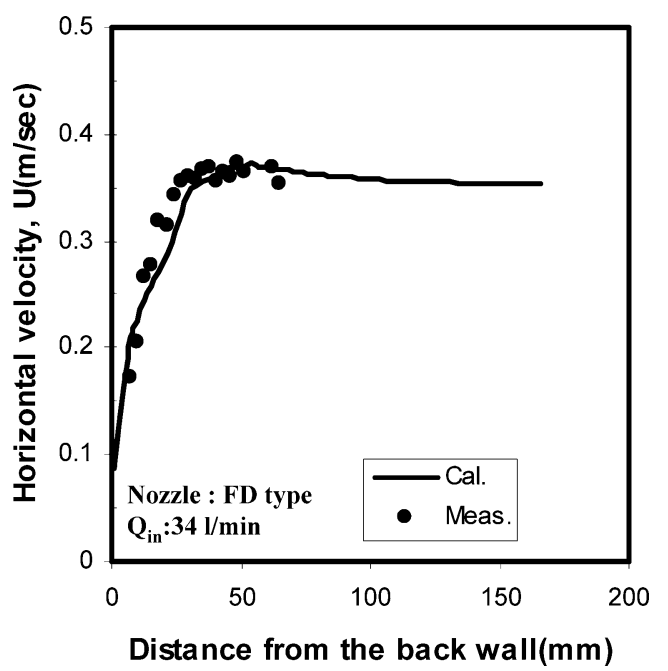

Fig. 13. Comparison of the measured and calculated velocities in the output chamber. away from the back wall) as shown in Figs. 15(b) and 15(c), the vertical velocity distributions are almost uniform except in the upper regions of the water films. For the velocity distribution outside the exit nozzle (or $170 \mathrm{~mm}$ away from the exit nozzle) as shown in Fig. 15(d), all of the velocities are $0.28 \mathrm{~m} / \mathrm{s}$. In other words, the vertical distributions of flow velocities across the thickness of water film are exactly same as the belt speed. This means that the iso-kinetic criterion can be perfectly satisfied outside the exit nozzle using the FD type nozzle. In addition, this iso-kinetic criterion can be nearly accomplished at other places such as near the triple point meniscus at the back wall, and at the entrance and exit of the exit nozzle, as shown in Figs. 15(a), 15(b) and 15(c).

Bubbles, generated during initial pouring, have to be removed as soon as possible to prevent disturbance of smooth surface flow and the formation of surface defects on the strip product. The time required for bubble removal from the output chamber was measured by a stopwatch for 10 min after starting pouring. The four different nozzles (Type $\mathrm{A}, \mathrm{B}, \mathrm{FC}$ and FD) were tested with three different starting methods: free start, $60 \mathrm{~mm} \mathrm{H}$ start and $150 \mathrm{~mm} \mathrm{H}$ start. "Free start" means starting without a starting stopper, and "60 mm H start" and " $150 \mathrm{~mm}$ H start" mean starting using a stopper when the water level arrives at the $60 \mathrm{~mm}$ and 150 $\mathrm{mm}$, respectively. Figure 16 shows the results. For the type A nozzle which has a slot nozzle without a multi-channel,

Distance from the back wall
(a) $5 \mathrm{~mm}$
(b) $30 \mathrm{~mm}$
(c) $120 \mathrm{~mm}$
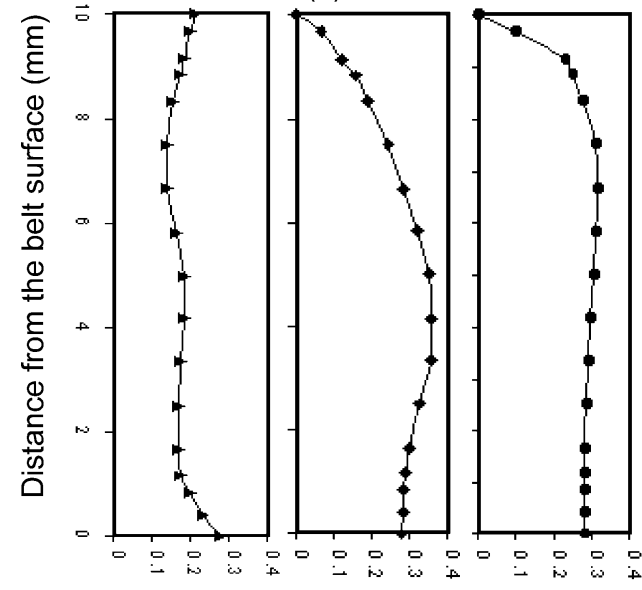

(d) $170 \mathrm{~mm}$

Calculated velocity $(\mathrm{m} / \mathrm{sec})$

Fig. 15. Calculated velocity distributions of water films generated on the moving belt with the distance from the back wall of the output chamber: (a) $5 \mathrm{~mm}$, (b) $30 \mathrm{~mm}$, (c) $120 \mathrm{~mm}$, and (d) $170 \mathrm{~mm}$.

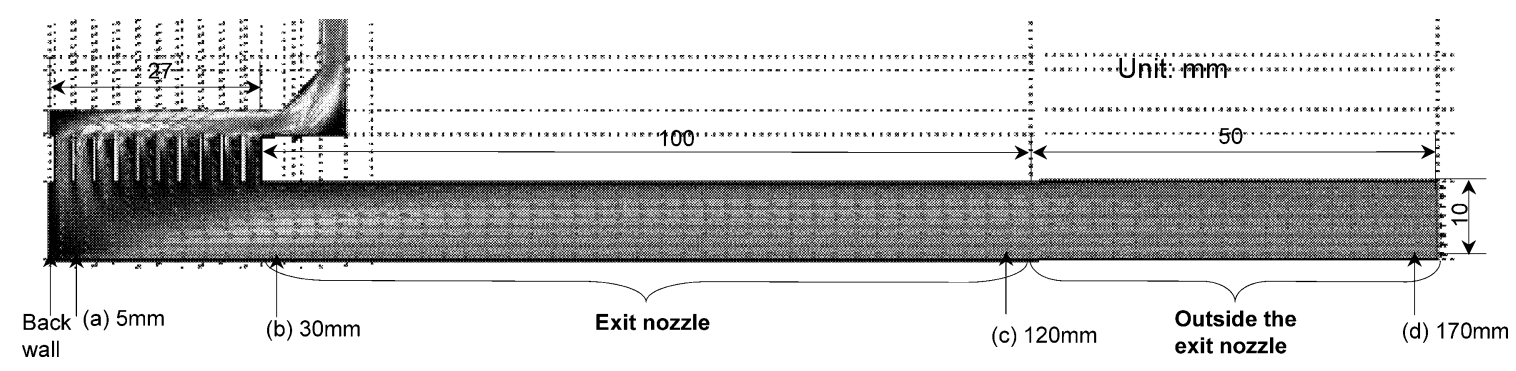

Fig. 14. Mathematical modeling for the FD type nozzle within the output chamber, the exit nozzle and outside the exit nozzle with moving belt. 


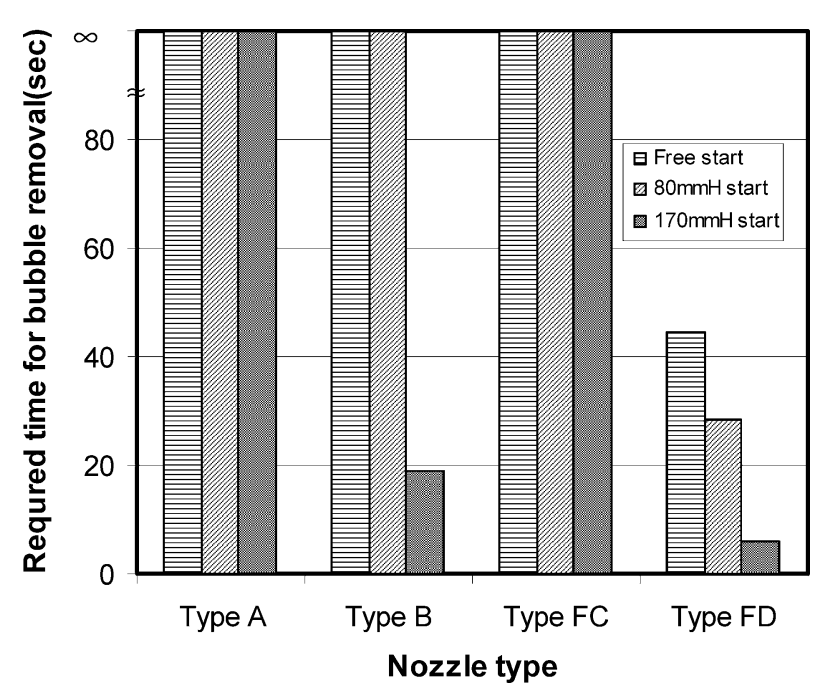

Fig. 16. Time required for bubble removal.

bubbles didn't disappear even for $150 \mathrm{~mm} \mathrm{H}$ start. When the 3-hole nozzle was used without the channel (Type B), bubbles were removed after $19 \mathrm{~s}$ pouring with the $150 \mathrm{~mm}$ $\mathrm{H}$ start. Bubbles remained during whole testing time when the FC type nozzle was used. The FD type nozzle shows outstanding performance for bubble removal. Bubbles were completely removed within $5 \mathrm{~s}$ for the $150 \mathrm{~mm}$ start and 30 $\mathrm{s}$ for $60 \mathrm{~mm} \mathrm{H}$ start, respectively.

Summarizing, the FD type nozzle led to a dramatic reduction in the strength of the vertically impinging flow towards the substrate. In addition, bubbles were completely removed from the output chamber using this nozzle. In this way, a uniform distribution of flow across the strip width and strip height could be generated at the exit nozzle, thereby respecting the criterion of iso-kinetic delivery of metal onto the moving belt of the single belt caster.

\section{Conclusions}

A piston type metal delivery system was designed for the single belt strip caster at McGill University. Water model equipment was set up to validate the proposed system. Water flows were inspected using dye injection, while velocity fields were measured with a dual Nd: YAG PIV for the several kinds of nozzles proposed for optimizing the metal delivery system. Mathematical modeling was also carried out to predict the flow pattern in the output chamber and determine its match with experiments. The following conclusions were drawn:

(1) When the type A nozzle, which had a slot type inlet nozzle without the flow modifier, was used, a strongly impinging jet flow was generated on a substrate and bubbles were entrapped within the re-circulatory flows in the output chamber.

(2) Bubbles were rapidly removed using the B type nozzle which had a three hole type inlet nozzle without a flow modifier, but the three impinging jets were not moderated.

(3) The FD type nozzle, which had a multi-channel as a flow modifier, a slot type inlet nozzle located at the right side of the multi-channel, and an upper chamber which had the same height with the inlet slot length, was found to be outstanding for bubble removal, moderating strongly impinging flows on the substrate, and providing uniform exit flows.

(4) Calculated flows were in good agreement with PIV measurements.

\section{Acknowledgement}

The authors wish to thank COMSOL Inc. (Burlington, MA, USA) for help with the FEMLAB program.

\section{REFERENCES}

1) W. R. Irving: Continuous Casting of Steel, University Press, Cambridge, (1993), 156.

2) W. D. Huskonen: 33 Metal Producing, 39 (2001), Iss.7, 24.

3) K. Schwerdtfeger: ISIJ Int., 38 (1998), No. 8, 852.

4) R. I. L. Guthrie, M. Isac and R. P. Tavares: Proc. on Fluid Flow Phenomena in Metals Processing, The Mineral, Metals \& Materials Society, Warrendale, PA, (1999), 307.

5) J. Herbertson and R. I. L. Guthrie: Proc. of Int. Symp. on Casting of Near Net Shape Products, AIME, New York, (1988), 335.

6) J. Kroos, T. Evertz, M. Dubke, U. Urlau and K. Spitzer: METEC Congress Proc., VDEh, Düsseldorf, Germany, (1999), 156.

7) G. Carlsson, R. Nystrom, H. Sandberg, W. Rechelt and U. Urlau: Scand. J. Metall., 26 (1997), 242.

8) Instruction manual for PIV system, TSI Incorporated, St. Paul, MN, USA, (2002).

9) B. E. Launder and D. B. Spalding: Comp. Meth. Appl. Mech. Eng., 3 (1974), 269.

10) B. Farouk, D. Apelian and Y. G. Kim: Metall. Trans. B, 23B (1992), 477.

11) D. Wilcox: Turbulence Modeling for CFD, DCW Industries Inc., La Canada, CA, USA, (1993), 44.

12) J. O. Hinze: Turbulence, 2nd ed., McGraw-Hill, New York, (1975), 586. 